\title{
Uber Future Value Prediction Using Discounted Cash Flow Model
}

\author{
Mengxiao Li \\ College of Urban Economics and Public Administration, Capital University of Economic and Business, Beijing, China \\ Email: Limengxiao190828@outlook.com
}

How to cite this paper: Li, M.X. (2020) Uber Future Value Prediction Using Discounted Cash Flow Model. American Journal of Industrial and Business Management, 10, 30-44.

https://doi.org/10.4236/ajibm.2020.101003

Received: November 27, 2019

Accepted: January 4, 2020

Published: January 7, 2020

Copyright $\odot 2020$ by author(s) and Scientific Research Publishing Inc. This work is licensed under the Creative Commons Attribution International License (CC BY 4.0).

http://creativecommons.org/licenses/by/4.0/

(c) (i) Open Access

\begin{abstract}
It is important to make a reasonable valuation of a company. A good valuation can make a difference in lots of aspects. In this research, the purpose of predicting valuation of Uber is to gain the future free cash flow and stock value of it, so that we can provide information for its future development strategy and put forward feasible business decisions, and then improve the future value of it. What's more, we hope to use the information of Uber's valuation to make investment analysis, understand its advantages and disadvantages, and help investors make better decisions. The reason why we choose Uber as a research object because it is a growing company that needs the right strategy and a lot of investments. Making valuation of Uber can help it attract investment and make stratagem. We use the discounted cash flow model to value Uber. We estimate the company's income, expenditure, free cash flow and equity beta in the future by investigating and studying its data in recent three years and the data of a peer group. Finally, we get Uber's optimistic price, pessimistic price and target price. All of the prices are higher than the present price which means it has a good development prospect and be good for investing.
\end{abstract}

\section{Keywords}

Discounted Cash Flow Model, Uber

\section{Introduction}

Uber is a Silicon Valley technology company which is famous for its taxi application. Uber has three major products and they are Personal Mobility, Uber Eats and Uber Freight. It covers more than 70 countries and over 400 cities in the world. Recently, Uber developed very well. In March 2019, Uber purchased the assets of Careem's subsidiaries and assumed all of their liabilities. Dubai-based 
Careem, founded in 2012, provides ridesharing, meal delivery, and payments services to millions of users in 115 cities across the Middle East, North Africa, and Pakistan. The purchase price for the acquisition is approximately $\$ 3.1$ billion, consisting of up to approximately $\$ 1.7$ billion of our unsecured convertible notes and approximately $\$ 1.4$ billion in cash, subject to certain adjustments. In April 2019, Uber entered into a Class A preferred unit purchase agreement with affiliates of SoftBank Vision Fund, Toyota Motor Corporation, and DENSO Corporation. And Toyota will provide advanced technologies group with $\$ 300$ million in cash, in semi-annual installments, to fund ongoing activities under the ATG partnership agreement. In April 2019, Uber entered into a stock purchase agreement with PayPal and they intend to explore future commercial payment collaborations, including the development of our digital wallet. On April 12, Uber submitted a prospectus to the SEC, which is expected to raise $\$ 10$ billion, with a valuation of up to $\$ 100$ billion. In 2019, Uber shares are traded on the New York Stock Exchange on May 10th. As the online car giant, Uber has landed on the New York Stock Exchange for an issue price of \$45. According to this calculation, the market value of Uber, which is fully diluted, will reach $\$ 82.4$ billion. Although the $\$ 45$ is the lower end of the previous issue range of $44-50$ US dollars, by the global stock market, Uber is still broken. Uber IPO opened at $\$ 42$ on the first day, down about $6.667 \%$ from the issue price. There is a certain gap between the estimate stock price and the price after Uber went to the public [1]. I think there are three reasons. First, Uber changes its strategy. For Uber, a very important sign in the future is that the price war will be a thing of the past. Uber's CFO Nelson Chai mentioned in a conference call after the first quarter earnings report that Uber will reduce customer promotions in order to reduce costs and reduce losses and Dara Knosrowshahi also said: "The focus of our real concern is to reduce service prices through the best technology on the market, rather than stimulate growth through discounts". The second reason is that many factors lead to the fierce competition. Such as the diversification, simple garrisoning conditions and technology development. These factors lead to the expansion of the market and the fierce competition. What's more, a lot of risk factors make some influence on the stock price, like decreasing costs, labor-capital relationship, and government regulation and so on. So there are lots of factors affect the stock price and it is necessary to estimate Uber's valuation in order to have a good development prospect and good for investing in the future.

It is very important to give a rational value to a high-tech company, which can be viewed as a guide for the public. However, there are many factors can be affected the valuation and also existed many valuation models. Different models may be suitable for different companies and different situations. Therefore, how to value Uber is still a problem. In this research, we calculate and estimate Uber's revenue, cost, equity beta, WACC and free cash flow in order to predict the stock price of Uber in the future. But because of the less information about Uber's revenue, cost and free cash flow and so on, it is a little difficult to value 
Uber in the future. What's more, Uber doesn't have the equity beta to calculate the Weighted Average Cost of Capital of Uber.

In this research, we use the Discounted Cash Flow model to value Uber because free cash flow is one of the most factors to estimate company's valuation and predict the development of company in the future. As you know, it is a little difficult to estimate Uber's valuation because of the less information. Therefore, we make the peer group which consists of Expedia, Booking Holding, Amazon, Netflix, Tesla and Grub Hub according to the companies' products, development strategy and business pattern to solve the problems. Finally, we estimate three models of Uber, one is the Uber valuation baseline, and according to the basis of the Baseline, we obtain the optimistic model and pessimistic model. The baseline's price is $\$ 51.23$, which means Uber's valuation will increase in the future with the trend of booming of technology and economics and people can make investments in Uber.

\section{Method}

Discounted cash flow (DCF) is a valuation method used to estimate the value of an investment based on its future cash flows. DCF analysis attempts to figure out the value of a company today, based on projections of how much money it will generate in the future. DCF analysis finds the present value of expected future cash flows using a discount rate. A present value estimate is then used to evaluate a potential investment. If the value calculated through DCF is higher than the current cost of the investment, the opportunity should be considered. Discounted Cash Flow model has three steps: the first is forecasting free cash flow to a limited extent within the defined forecast period (usually 5 to 10 years); the second is calculating the predicted level of free cash flow based on the simplified model assumptions; and finally discounting the free cash flow based on the weighted average cost of capital (WACC). In this project, Discounted Cash Flow (DCF) model is used to predict Uber's future income, expenditure and stock price. The Discounted Free Cash Flow Model evaluates the firm's business and its profitability. It estimates the firm's Enterprise Value, which is the value of the business, separate from corporate savings in cash and marketable securities. The Discounted FCF model values the firm without forecasting payout policies or funding strategies. In the DCF, it is important to calculate revenue, cost, equity beta, WACC and free cash flow. Next, we will explain and analyze our model step by step.

\section{Results and Discussion}

\section{1) Revenue}

The revenue forecast is based on the gross booking of the platform in our model. The gross booking of platform is defined as the total dollar value, including any applicable taxes, tolls, and fees of Ridesharing and New Mobility rides, Uber Eats meal deliveries, and amounts paid by shippers for Uber Freight shipments, in each case without any adjustment for consumer discounts and re- 
funds, driver and restaurant earnings, and driver incentives. Gross Bookings do not include tips earned by drivers. We found Uber material, S-1, from the SEC to calculate the gross bookings about Uber platform from 2017 to 2018 to make predictions [1].

By calculating the existing historical data, we can get:

As shown in Table 1, ridesharing's gross booking increased 32\% from 2017 to 2018 , with ridesharing's revenue accounting for $22 \%$ of its booking growth. About Uber Eats, its gross bookings by $168 \%$ during that period, while its revenue share of that growth fell by $1.4 \%$. Ridesharing and Uber Eats are the two biggest businesses on the platform of Uber, and they also account for the majority of Uber's revenue. Uber also explicitly stated in S-1 that it would increase its investment in ridesharing and Uber Eats [1]. As shown in Table 2, so we predicted that ridesharing and Uber Eats would increase their reservation growth in the future. But their growth rate would decrease due to the gradual saturation of the market, and we predicted that its growth rate would converge to $8 \%$ in the long-run. For ridesharing and Uber Eats to account for a growing share of gross booking, we expect it will grow in the future. Due to the development of science and technology, artificial intelligence plays an important role in various fields. In the future, the emergence of unmanned driving will reduce the demand for drivers. And under the assumption that drivers are not required to pay, the proportion of revenue in the growth of platform reservation will continue to increase.

As shown in Table 3, it shows the revenue of Uber's other core platform and other bets from 2017 to 2019. Uber's revenue projections include four sections: Ridesharing, Uber Eats, other core platform and other bets. Other revenue consists of revenue associated with our Vehicle Solutions activities. Other bets refer to one of the two operating segments that we use to manage our business. Other Bets in 2017 consisted primarily of Uber Freight and in 2018 also included New Mobility.

From 2017 to 2018, the growth rate of other cores is negative, and Uber also made the decision that the future will not use it as a major project to invest, but we think Uber might find the solution about the question of negative growth. So as shown in Table 4, we predict the growth rate of another core platform will increase or be positive in the future. We predict the growth rate is $10 \%$. With an annual growth rate of other bets is $457 \%$ in 2017 and decrease down to $50 \%$ in 2018. We expect other bets' revenue to continue to grow, but not at such a high rate. And the growth rate will gradually slow down. So we expect its growth rate to approach $10 \%$ in the future (Table 4 ).

Table 5 shows the total revenue from 2017 to 2019. Uber's revenue is the sum of ridesharing, Uber Eats, other core platform and other bets. And we can obtain Uber's revenue projections for the next ten years by summarizing the above projections. As shown in Table 6, based on this prediction, we calculated the growth rate of Uber's revenue that gradually slowed from 34\% in 2019 to nearly $12 \%$ a decade later. 
Table 1. Revenue forecasting of ridesharing and uber eats (2017-2019) [1].

\begin{tabular}{cccc}
\hline & 2017 & 2018 & 2019 \\
\hline Gross booking, ridesharing & $\$ 31,384$ & $\$ 41,513$ & $\$ 53,137$ \\
Inc. \% & & $32 \%$ & $28.0 \%$ \\
Revenue, ridesharing & $\$ 6888$ & $\$ 9182$ & $\$ 12,753$ \\
$R / G B$ & $21.9 \%$ & $22.1 \%$ & $24.0 \%$ \\
Gross booking, Uber Eats & $\$ 2958$ & $\$ 7919$ & $\$ 14,254$ \\
Inc. \% & & $168 \%$ & $80 \%$ \\
Revenue, Uber Eats & $\$ 587$ & $\$ 1460$ & $\$ 2851$ \\
$R / G B$ & $19.8 \%$ & $18.4 \%$ & $20.0 \%$ \\
\hline
\end{tabular}

Table 2. Revenue forecasting of ridesharing and uber eats (2020-2027).

\begin{tabular}{ccccccccc}
\hline & 2020 & 2021 & 2022 & 2023 & 2024 & 2025 & 2026 & 2027 \\
\hline $\begin{array}{c}\text { Gross } \\
\text { booking, } \\
\text { ridesharing }\end{array}$ & $\$ 65,358$ & $\$ 77,123$ & $\$ 88,691$ & $\$ 97,560$ & $\$ 105,365$ & $\$ 113,794$ & $\$ 122,897$ & $\$ 132,729$ \\
Inc. \% & $23.0 \%$ & $18.0 \%$ & $15 \%$ & $10 \%$ & $8 \%$ & $8 \%$ & $8 \%$ & $8 \%$ \\
$\begin{array}{c}\text { Revenue, } \\
\text { ridesharing }\end{array}$ & $\$ 16,340$ & $\$ 20,052$ & $\$ 23,947$ & $\$ 27,317$ & $\$ 30,556$ & $\$ 34,138$ & $\$ 38,098$ & $\$ 42,473$ \\
$\begin{array}{c}R / G B \\
\text { Gross }\end{array}$ & $25.0 \%$ & $26.0 \%$ & $27.0 \%$ & $28.0 \%$ & $29.0 \%$ & $30.0 \%$ & $31.0 \%$ & $32.0 \%$ \\
$\begin{array}{c}\text { booking, } \\
\text { Uber Eats }\end{array}$ & $\$ 21,381$ & $\$ 27,796$ & $\$ 33,355$ & $\$ 38,358$ & $\$ 42,194$ & $\$ 45,569$ & $\$ 49,215$ & $\$ 53,152$ \\
$\begin{array}{c}\text { Inc. \% } \\
\text { Revenue, }\end{array}$ & $50 \%$ & $30 \%$ & $20 \%$ & $15 \%$ & $10 \%$ & $8 \%$ & $8 \%$ & $8 \%$ \\
$\begin{array}{c}\text { Uber Eats } \\
R / G B\end{array}$ & $21.0 \%$ & $22.0 \%$ & $23.0 \%$ & $24.0 \%$ & $25.0 \%$ & $26.0 \%$ & $27.0 \%$ & $28.0 \%$
\end{tabular}

Table 3. Revenue forecasting of other core platform and other bets (2017-2019) [1].

\begin{tabular}{cccc}
\hline & 2017 & 2018 & 2019 \\
\hline Inc. \% & $\$ 390$ & $\$ 255$ & $\$ 383$ \\
Revenue, other bets & $\$ 67$ & $-35 \%$ & $50 \%$ \\
Inc. $\%$ & & $\$ 373$ & $70 \%$ \\
\hline
\end{tabular}

Table 4. Revenue forecasting of other core platform and other bets (2020-2027).

\begin{tabular}{ccccccccc}
\hline & 2020 & 2021 & 2022 & 2023 & 2024 & 2025 & 2026 & 2027 \\
\hline $\begin{array}{c}\text { Revenue, other } \\
\text { core platform }\end{array}$ & $\$ 497$ & $\$ 597$ & $\$ 686$ & $\$ 755$ & $\$ 830$ & $\$ 913$ & $\$ 1005$ & $\$ 1105$ \\
$\begin{array}{c}\text { Inc. \% } \\
\begin{array}{c}\text { Revenue, } \\
\text { other bets }\end{array}\end{array}$ & $\$ 0 \%$ & $20 \%$ & $15 \%$ & $10 \%$ & $10 \%$ & $10 \%$ & $10 \%$ & $10 \%$ \\
Inc. \% & $50 \%$ & $\$ 1236$ & $\$ 1484$ & $\$ 1632$ & $\$ 1795$ & $\$ 1975$ & $\$ 2172$ & $\$ 2390$ \\
\hline
\end{tabular}


Table 5. Revenue forecasting (2017-2019) [1].

\begin{tabular}{cccc}
\hline & 2017 & 2018 & 2019 \\
\hline Revenue & $\$ 7932$ & $\$ 11,270$ & $\$ 16,620$ \\
Inc. \% & & $42 \%$ & $47 \%$ \\
\hline
\end{tabular}

Table 6. Revenue forecasting (2020-2027).

\begin{tabular}{ccccccccc}
\hline & 2020 & 2021 & 2022 & 2023 & 2024 & 2025 & 2026 & 2027 \\
\hline Revenue & $\$ 22,278$ & $\$ 28,000$ & $\$ 33,788$ & $\$ 38,910$ & $\$ 43,730$ & $\$ 48,874$ & $\$ 54,563$ & $\$ 60,851$ \\
Inc. \% & $34 \%$ & $26 \%$ & $21 \%$ & $15 \%$ & $12 \%$ & $12 \%$ & $12 \%$ & $12 \%$ \\
\hline
\end{tabular}

\section{2) MAPCs and ARPU}

When measuring Uber's progress, we look at the growth in bookings, and also consider about MAPCs, ARPU and Trips. MAPCs means as the number of unique consumers who completed a Ridesharing or New Mobility ride or received an Uber Eats meal on our platform at least once in a given month, averaged over each month in the quarter [1]. MAPCs presented for an annual period are MAPCs for the fourth quarter of the year. ARPU refers to the revenue generated by each customer using the Uber platform. Trips refer to the number of consumer ride-sharing or new mobile trips completed in a given period of time.

As shown in Table 7, the MAPCs are 68 in 2017 and ARPU is \$117 in 2017. And in 2019 the MAPCs are up to the 100 and ARPU is up to $\$ 166$.

As shown in Table 8, we predict MAPCs in the model to be 100 million in 2019 and grow to 172 million in 2027 . We divide the total revenue by MAPCs and get ARPU.

\section{3) Cost}

Uber's expenditure is divided into three parts, including Cost of Sales, R\&D and SG\&A. From the data obtained from S-1, we can calculate that the ratio of Cost of Sales to revenue from 2017 to 2018 is $52 \%$ and $50 \%$ as shown in Table 9 [1]. As shown in Table 10, with the change of technology and the development of the company, we predict that the cost of sales will account for less and less of the revenue, approaching $28 \%$ in the future. $R \& D$ refers to the research and development cost of the company. As Uber is an innovative technology company and its future development strategy is also planned in the direction of drone driving, which requires more $R \& D$ costs. So we believe that the proportion of $\mathrm{R} \& \mathrm{D}$ in revenue will not decline. Based on the historical data, we can calculate that the proportion of $\mathrm{R} \& \mathrm{D}$ in revenue in recent two years is $15 \%$ and $13 \%$, respectively. Therefore, we predict that the proportion of $R \& D$ in revenue in the next ten years is $13 \%$. SG\&A refers to the company's selling, general, and administrative expenditure. The SG\&A of Uber has a significant decline from $90 \%$ in 2016 to $60 \%$ in 2018 . We believe that with the development of Uber, its SG\&A ratio will continue to decline. 
Table 7. Forecasting of MAPCs and ARPU (2017-2019) [1].

\begin{tabular}{cccc}
\hline & 2017 & 2018 & 2019 \\
\hline MAPCs & 68 & 91 & 100 \\
Inc. \% & & $34 \%$ & $10 \%$ \\
ARPU & $\$ 117$ & $\$ 124$ & $\$ 166$ \\
Inc. \% & & $6 \%$ & $34 \%$ \\
\hline
\end{tabular}

Table 8. Forecasting of MAPCs and ARPU (2020-2027).

\begin{tabular}{ccccccccc}
\hline & 2020 & 2021 & 2022 & 2023 & 2024 & 2025 & 2026 & 2027 \\
\hline MAPCs & 109 & 118 & 127 & 136 & 145 & 154 & 163 & 172 \\
Inc. \% & $9 \%$ & $8 \%$ & $8 \%$ & $7 \%$ & $7 \%$ & $6 \%$ & $6 \%$ & $6 \%$ \\
ARPU & $\$ 204$ & $\$ 237$ & $\$ 266$ & $\$ 286$ & $\$ 302$ & $\$ 317$ & $\$ 335$ & $\$ 354$ \\
Inc. \% & $23 \%$ & $16 \%$ & $12 \%$ & $8 \%$ & $5 \%$ & $5 \%$ & $5 \%$ & $6 \%$ \\
\hline
\end{tabular}

Table 9. Forecasting of cost (2017-2019) [1].

\begin{tabular}{cccc}
\hline & 2017 & 2018 & 2019 \\
\hline Cost of Sales & $\$ 4160$ & $\$ 5623$ & $\$ 7064$ \\
$\%$ of $\operatorname{ReV}$ & $52 \%$ & $50 \%$ & $43 \%$ \\
Research Development & $\$ 1201$ & $\$ 1505$ & $\$ 2493$ \\
\% of $\operatorname{ReV}$ & $15 \%$ & $13 \%$ & $15 \%$ \\
SG\&A of $\operatorname{ReV}$ & $\$ 6141$ & $\$ 6749$ & $\$ 7479$ \\
& $77 \%$ & $60 \%$ & $45 \%$ \\
\hline
\end{tabular}

Table 10. Forecasting of cost (2020-2027).

\begin{tabular}{ccccccccc}
\hline & 2020 & 2021 & 2022 & 2023 & 2024 & 2025 & 2026 & 2027 \\
\hline Cost of Sales & $\$ 8911$ & $\$ 9800$ & $\$ 10,136$ & $\$ 10,895$ & $\$ 12,244$ & $\$ 13,685$ & $\$ 15,278$ & $\$ 17,038$ \\
$\%$ of $\operatorname{ReV}$ & $40 \%$ & $35 \%$ & $30 \%$ & $28 \%$ & $28 \%$ & $28 \%$ & $28 \%$ & $28 \%$ \\
$\begin{array}{c}\text { Research } \\
\text { Development }\end{array}$ & $\$ 3342$ & $\$ 4200$ & $\$ 5068$ & $\$ 5836$ & $\$ 6559$ & $\$ 7331$ & $\$ 8185$ & $\$ 9128$ \\
$\%$ of $\operatorname{ReV}$ & $15 \%$ & $15 \%$ & $15 \%$ & $15 \%$ & $15 \%$ & $15 \%$ & $15 \%$ & $15 \%$ \\
SG\&A & $\$ 8911$ & $\$ 9800$ & $\$ 11,150$ & $\$ 11,673$ & $\$ 13,119$ & $\$ 14,662$ & $\$ 16,369$ & $\$ 18,255$ \\
$\%$ of $\operatorname{ReV}$ & $40 \%$ & $35 \%$ & $33 \%$ & $30 \%$ & $30 \%$ & $30 \%$ & $30 \%$ & $30 \%$ \\
\hline
\end{tabular}

\section{4) EBIT}

Based on the above data and forecast, we can calculate Uber's EBIT by using the formula of income and expenditure as shown in Table 11. EBIT refers to the profit before interest and income tax.

As shown in Table 12, we can get the EBIT from 2017 to 2019.

\section{5) Capital Expenditure}

Capital Expenditures are funds used by a company to acquire, upgrade, and maintain physical assets such as property, buildings, an industrial plant, technology, or equipment. It is calculated using the formula below. 
Table 11. Forecasting of EBIT (2020-2027).

\begin{tabular}{ccccccccc}
\hline & 2020 & 2021 & 2022 & 2023 & 2024 & 2025 & 2026 & 2027 \\
\hline Revenue & $\$ 18,761$ & $\$ 22,516$ & $\$ 26,324$ & $\$ 30,050$ & $\$ 33,667$ & $\$ 37,672$ & $\$ 42,103$ & $\$ 47,003$ \\
Inc. $\%$ & $24 \%$ & $20 \%$ & $17 \%$ & $14 \%$ & $12 \%$ & $12 \%$ & $12 \%$ & $12 \%$ \\
Cost of Sales & $\$ 7504$ & $\$ 7881$ & $\$ 7897$ & $\$ 9015$ & $\$ 10,100$ & $\$ 11,302$ & $\$ 12,631$ & $\$ 14,101$ \\
\% of Rev & $40 \%$ & $35 \%$ & $30 \%$ & $30 \%$ & $30 \%$ & $30 \%$ & $30 \%$ & $30 \%$ \\
$\begin{array}{c}\text { Research } \\
\text { Development }\end{array}$ & $\$ 2439$ & $\$ 2927$ & $\$ 3422$ & $\$ 3906$ & $\$ 4377$ & $\$ 4897$ & $\$ 5473$ & $\$ 6110$ \\
$\%$ of $\operatorname{Rev}$ & $13 \%$ & $13 \%$ & $13 \%$ & $13 \%$ & $13 \%$ & $13 \%$ & $13 \%$ & $13 \%$ \\
SG\&A & $\$ 7504$ & $\$ 7881$ & $\$ 8687$ & $\$ 9015$ & $\$ 10,100$ & $\$ 11,302$ & $\$ 12,631$ & $\$ 14,101$ \\
\% of Rev & $40 \%$ & $35 \%$ & $33 \%$ & $30 \%$ & $30 \%$ & $30 \%$ & $30 \%$ & $30 \%$ \\
EBIT & $\$ 1313$ & $\$ 3828$ & $\$ 6318$ & $\$ 8113$ & $\$ 9090$ & $\$ 10,172$ & $\$ 11,368$ & $\$ 12,691$ \\
\hline
\end{tabular}

Table 12. Forecasting of EBIT (2017-2019).

\begin{tabular}{cccc}
\hline & 2017 & 2018 & 2019 \\
Revenue & $\$ 7932$ & $\$ 11,270$ & $\$ 15,108$ \\
Inc. $\%$ & & $42 \%$ & $34 \%$ \\
Cost of Sales & $\$ 4160$ & $\$ 5623$ & $\$ 6799$ \\
\% of Rev & $52 \%$ & $50 \%$ & $45 \%$ \\
Research Development & $\$ 1201$ & $\$ 1505$ & $\$ 1964$ \\
\% of Rev & $15 \%$ & $13 \%$ & $13 \%$ \\
SG\&A & $\$ 6141$ & $\$ 6749$ & $\$ 7252$ \\
of $\operatorname{Rev}$ & $77 \%$ & $60 \%$ & $48 \%$ \\
EBIT & $(\$ 3570)$ & $(\$ 2607)$ & $(\$ 906)$ \\
\hline
\end{tabular}

CapEx $=\Delta \mathrm{PP} \& \mathrm{E}+$ Current Depreciation

where:

CapEx $=$ Capital expenditures.

$\triangle \mathrm{PP} \& \mathrm{E}=$ Change in property, plant, and equipment.

In our model, we believe Uber will continue to expand its scale in the future, which means its investment in physical assets will rise, including constructing new branches, maintaining larger amount of servers and acquiring its potential or existing competitors. As a result, capital expenditure shows an upward trend in our prediction, but it accounts for a steady proportion of the increase in revenue as shown in Table 13.

In the long run, the percentage of increase in revenue that capital expenditures account for tends to plateau in most businesses, and the fact helps us to determine the steady trend. Also, according to historical data from statement of cash flow in Uber's SEC S-1 document and the calculated results, they were already in a relatively referable range, so we took the average, which is approximately $6 \%$ as shown in Table 14 . 
Table 13. Forecasting of capital expenditure (2017-2019).

\begin{tabular}{cccc}
\hline & 2017 & 2018 & 2019 \\
\hline Capital Expenditure & $\$ 829$ & $\$ 558$ & $\$ 906$ \\
$\%$ of Inc., Rev & $10 \%$ & $5 \%$ & $6 \%$ \\
\hline
\end{tabular}

Table 14. Forecasting of capital expenditure (2020-2027).

\begin{tabular}{ccccccccc}
\hline & 2020 & 2021 & 2022 & 2023 & 2024 & 2025 & 2026 & 2027 \\
\hline Capital Expenditure & $\$ 1126$ & $\$ 1351$ & $\$ 1579$ & $\$ 1803$ & $\$ 2020$ & $\$ 2260$ & $\$ 2526$ & $\$ 2820$ \\
$\%$ of Inc., $\operatorname{ReV}$ & $6 \%$ & $6 \%$ & $6 \%$ & $6 \%$ & $6 \%$ & $6 \%$ & $6 \%$ & $6 \%$ \\
\hline
\end{tabular}

\section{6) Net Working Capital (NWC)}

Working capital is a measure of a company's liquidity, operational efficiency and its short-term financial health. If a company has substantial working capital, then it should have the potential to invest and grow, so in our projections, we would give Uber an increasing NWC. The formula is shown below:

Net Working Capital $=$ Cash Requirements + Inventory + Receivables - Payables .

Uber does not have any inventory due to the features of the company, so NWC for Uber is

$$
\text { Net Working Capital }=\text { Cash Requirements }+ \text { Receivables }- \text { Payables } \text {. }
$$

We adopted cash, receivables and payables from the balance sheet in Uber's SEC S-1 document and obtained the historical data 490 and 472 in 2017 and 2018 respectively.

Any increases in net working capital represent an investment that reduces the cash available to the firm and so reduces free cash flow. The increase in net working capital in year $t$ is defined as

$$
\Delta \mathrm{NWC}_{t}=\mathrm{NWC}_{t}-\mathrm{NWC}_{t-1} .
$$

Similar to CapEx, $\triangle \mathrm{NWC}$ is usually presented as a fraction of the increase in revenue as shown below

In Table 15, we can see the increase in NWC between 2017 and 2019.

As shown in Table 16, we use data of previous years, the trend of $\triangle \mathrm{NWC}$ was uncertain, even though the percentage below rose, the exact number fell. Therefore, predictions of figures are commonly made based on the percentage of increase in revenue, which was stable in the case of Uber, and we decided to carry forward this percentage. It is important to realize the NWC will increase anyway in the future even though $\triangle \mathrm{NWC}$ will not always rise compared to the previous year in the future, which fits the assumption that Uber will be able to continue to improve its financial condition.

\section{7) Free Cash Flow (FCF)}

Free cash flow represents the cash a company generates after cash outflows to support operations and maintain its capital assets. Unlike earnings or net income, free cash flow is a measure of profitability that excludes the non-cash expenses of the income statement and includes spending on equipment and assets as well as changes in working capital. The formula is: 
Table 15. Forecasting of increase in NWC (2017-2019).

\begin{tabular}{rccc}
\hline & 2017 & 2018 & 2019 \\
\hline Increse in NWC & $\$ 490$ & $\$ 472$ & $\$ 537$ \\
\% of Inc. ReV & $12 \%$ & $14 \%$ & $14 \%$ \\
\hline
\end{tabular}

Table 16. Forecasting of increase in NWC (2017-2019).

\begin{tabular}{ccccccccc}
\hline & 2020 & 2021 & 2022 & 2023 & 2024 & 2025 & 2026 & 2027 \\
\hline Increse in NWC & $\$ 511$ & $\$ 526$ & $\$ 533$ & $\$ 522$ & $\$ 506$ & $\$ 561$ & $\$ 620$ & $\$ 686$ \\
\% of Inc. ReV & $14 \%$ & $14 \%$ & $14 \%$ & $14 \%$ & $14 \%$ & $14 \%$ & $14 \%$ & $14 \%$ \\
\hline
\end{tabular}

$$
\begin{aligned}
\text { Free Cash Flow }= & (\text { Revenues }- \text { Costs }- \text { Depreciation }) \times(1-\text { Tax rate }) \\
& + \text { Depreciation }- \text { CapEx }-\Delta \text { NWC }
\end{aligned}
$$

Then we obtained the annual free cash flow, where numbers in red and brackets represent negative free cash flow.

As shown in Table 17 and Table 18, we can get Free Cash Flow from 2017 to 2027. According to the data, we predict the FCF is $\$ 8400$ in 2027.

\section{8) Uber's Cost of Capital}

Next, we want to calculate the Uber's cost capital. The Capital Asset Pricing Model (CAPM) implies that:

$$
r_{\text {Uber }}=r_{f}+\beta\left(r_{M}+r_{f}\right) .
$$

To calculate the return on Uber stock, we need the Equity Beta of Uber. In order to calculate Uber's Equity Beta, we selected six companies as a peer group, namely Expedia, Booking Holding, Amazon, Netflix, Tesla and Grub Hub.

The reason why we choose Expedia and Booking Holding is that these two companies are similar to Uber in terms of revenue calculation, all they need Gross Booking as the basis. Meanwhile, these two companies are third-party platforms like Uber and have similar profit models. The reason why we choose Tesla is that it has the same development strategy and prospect with Uber, both of them hope to develop self-driving technology and apply it to products in the future. Moreover, the reason for choosing Amazon is that it is an e-commerce platform like Uber. Amazon shows products to customers through the platform, and Uber provides information and ways of service to customers through the platform. Both are third-party platforms and have the same sales method. The reason for choosing Netflix is that Netflix provides film and television information to consumers through the platform while Uber provides service information to consumers through the platform. Consumers enjoy the convenience and service brought by Netflix and Uber through the platform. Finally, Grub Hub is selected because it has the same products as Uber as a delivery platform, which is more in line with the setting of the industry and has more reference value in terms of risk assessment and profit model. 
Table 17. Forecasting of free cash flow (2017-2019).

\begin{tabular}{cccc}
\hline & 2017 & 2018 & 2019 \\
\hline Free Cash Flow & $(\$ 4379)$ & $(\$ 3211)$ & $(\$ 1746)$ \\
\hline
\end{tabular}

Table 18. Forecasting of free cash flow (2017-2019).

\begin{tabular}{rrrrrrrrr}
\hline & 2020 & 2021 & 2022 & 2023 & 2024 & 2025 & 2026 & 2027 \\
\hline Free Cash Flow & $\$ 427$ & $\$ 2456$ & $\$ 3932$ & $\$ 5287$ & $\$ 6001$ & $\$ 6721$ & $\$ 7518$ & $\$ 8400$ \\
\hline
\end{tabular}

As shown in Figure 1, $r_{f}$ means risk-free rate of returns and $r_{M}$ means the return on the market portfolio. The $r_{M}$ is defined by the Tobin's Cloud, we need Tobin's Cloud. In Tobin's Cloud, E represents expected value, and SD represents standard deviation. And for each $\mathrm{R}$, we want a higher $\mathrm{E}$ and a smaller SD. If we have $r_{f}$ and Tobin's Cloud, we can only find the best $r_{M}$. Because if $r_{M}$ is in the position of $r_{1}$ in the figure below, then any point in the region has a higher $\mathrm{E}$ and a lower SD than $r_{1}$. So what we are looking for is a line that crosses $r_{f}$ and has only one intersection point with Tobin's Cloud, and that intersection point is $r_{M}$.

If we find $r_{M}$, so sharp ration of $r_{M}$ is equal to:

$$
\frac{E\left(r_{M}\right)-r_{f}}{S D\left(r_{M}\right)}=\max _{r}\left(\frac{E\left(r_{M}-r_{f}\right)}{S D\left(r_{M}\right)}\right)
$$

And then,

$$
\frac{E\left(r_{i}\right)-r_{f}}{\operatorname{Corr}\left(r_{i}, r_{M}\right) S D\left(r_{i}\right)}=\frac{E\left(r_{M}\right)-r_{f}}{S D\left(r_{M}\right)}
$$

So the formula for calculating the return on stocks would be:

$$
r_{i}=r_{f}+\operatorname{Corr}\left(r_{i}, r_{M}\right) \times \frac{S D\left(r_{i}\right)}{S D\left(r_{M}\right)} \times E\left(r_{M}-r_{f}\right)
$$

And beta is equal to:

$$
\beta=\operatorname{Corr}\left(r_{i}, r_{M}\right) \times \frac{S D\left(r_{i}\right)}{S D\left(r_{M}\right)} .
$$

After that, we found the relevant data of calculating Beta on Yahoo and calculated the Equity Beta of six companies. And according to these data and applied the formula to form the following prediction line. Taking Amazon as an example:

Through calculation, we can get:

$$
y=1.6037 x+0.0241
$$

As shown in Figure 2, the number 1.6037 is Amazon's Equity Beta, and the number 0.0241 is an error.

By calculating the six companies we selected and predicting Uber's Equity Beta based on the Equity Beta of the six companies. We can get the following conclusions (Table 19). 


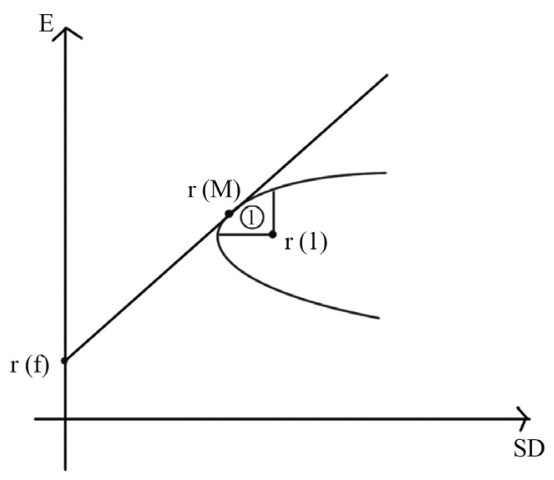

Figure 1. Tobin's cloud.

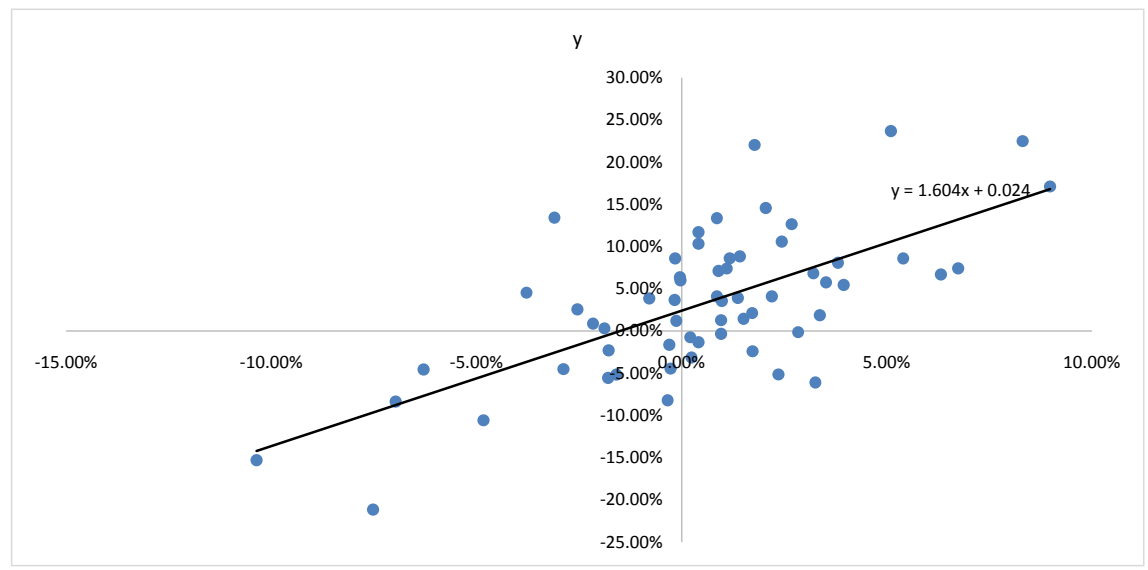

Figure 2. Amazon's beta.

Table 19. Equity beta.

\begin{tabular}{cc}
\hline Company & 5Y Equity Beta \\
\hline Uber & $1.165[2]$ \\
Amazon & $1.604[3][4]$ \\
Tesla & $0.817[5][6]$ \\
Expedia & $1.066[7][8]$ \\
Grub Hub & $1.281[9][10]$ \\
Netflix & $1.246[11][12]$ \\
Booking & $1.175[13][14]$ \\
\hline
\end{tabular}

\section{9) Weighted Average Cost of Capital (WACC)}

The weighted average cost of capital (WACC) is a calculation of a firm's cost of capital in which each category of capital is proportionately weighted. All sources of capital, including common stock, preferred stock, bonds, and any other long-term debt, are included in a WACC calculation.

A firm's WACC increases as the beta and rate of return on equity increase because an increase in WACC denotes a decrease in valuation and an increase in risk.

The formula for WACC is shown below: 


$$
\mathrm{WACC}=\frac{E}{E+N e t D e b t} \times R_{e}+\frac{N e t D e b t}{E+N e t D e b t} \times R_{d} \times(1-T)
$$

where:

$R_{e}=$ Cost of equity.

$R_{d}=$ Cost of debt $=$ Risk free rate + Debt Beta $\times$ market risk premium.

$E=$ Market value of the firm's equity.

$N D=$ Firm's net debt $=$ Debt-Cash.

$E+D=$ Total market value of the firm's financing.

$E /(E+D)=$ Percentage of financing that is equity.

$D /(E+D)=$ Percentage of financing that is debt.

$T=$ Corporate tax rate $=21 \%$.

It is worth mentioning that Debt Beta was an estimation of 0.2, which is an average for common businesses. Market risk premium is generally between $5 \%$ and $6 \%$, in Uber's case we used $6 \%$ as an approximation. The risk-free rate is the return rate of 13-week U.S. Treasury Bill since it barely involves any risks due to the government's ability to print money to pay back if it lacks money in the future. Then, both market capitalization and net debt are extracted from financials online, including Yahoo Finance and balance sheet in Uber's SEC document respectively.

\section{0) Enterprise Value}

The next step is to discount them in order to calculate their present value, also known as the enterprise value, which needs the formula

$$
V_{0}=\frac{F C F_{2019}}{1+r_{\text {wacc }}}+\frac{F C F_{2020}}{\left(1+r_{\text {wacc }}\right)^{2}}+\cdots+\frac{F C F_{2028}+V_{N}}{\left(1+r_{\text {wacc }}\right)^{10}}
$$

We used the firm's WACC, denoted by $r_{\text {wacc }}$, which is the average cost of capital the firm must pay to all of its investors, both debt and equity holders. If the firm has no debt, then $r_{\text {wacc }}=r_{E}$. But when a firm has debt, $r_{\text {wacc }}$ is an average of the firm's debt and equity cost of capital.

Next we compute the $V_{N}$, the terminal value estimated by assuming a constant long-run growth rate $g_{F C F}$ for free cash flows beyond year N (in our case 2028), so that

$$
V_{N}=\left(\frac{1+g_{F C F}}{r_{\text {wacc }}-g_{F C F}}\right) \times F C F_{2028}
$$

The long-run growth rate $g_{F C F}$ is typically based on the expected long-run growth rate of the firm's revenues, which was set to $2.0 \%$ as a conservative figure, because we are uncertain about how dramatically Uber will expand in the future.

11) Price Target

Using the formula

$$
\text { Enterprise Value }=\text { Equity Value }+ \text { Debt }- \text { Cash }
$$

And rearrange it we get 


$$
\text { Equity Value }=\text { Enterprise Value }- \text { Debt }+ \text { Cash }
$$

Where Equity Value is number of shares outstanding $\times$ per share price, which is 1696 million.

\section{2) Optimistic model and pessimistic model}

Based on our model, we obtain the Uber's valuation baseline and the target price is $\$ 51.23$. It means that Uber will has better expression in the future. On the basis of the Baseline, we predict the optimistic model and pessimistic model as shown in Figure 3.

The optimistic model is named the Blue Sky and the price is $\$ 65.73$. We improve the growth rate of gross booking on baseline and the ratio of revenue to gross booking. This is because we predict that Uber's gross booking will also have a high growth rate on the premise of a good market prospect and rapid development of Uber. We reduce the growth rate of cost of sales, because we believe that in the premise of rapid development of Uber technology in the future, the cost of sales will decrease. On the SG\&A side, we increased its growth rate because we believe that as Uber grows rapidly, its sell, general and administrative expenses will increase.

The major assumption in the pessimistic model is the failure in the development of autonomous driving technology, which will reduce the growth rate of the proportion of revenue account for gross bookings. We also predict a more competitive market, where Uber will promote its businesses more heavily. This causes the costs to rise.

\section{Conclusion}

Since our price target of $\$ 51.23$ exceeds the current share price of $\$ 43$ [2], which implies that Uber will outperform in its future operations. We encourage people to add Uber's stock into portfolio. However, due to several potential risk factors, we advise people to consider carefully before investment. This model can also be applied to the valuation of other companies to analyze the company's situation and make plans. This kind of valuation can help the company make better planning and get better development.

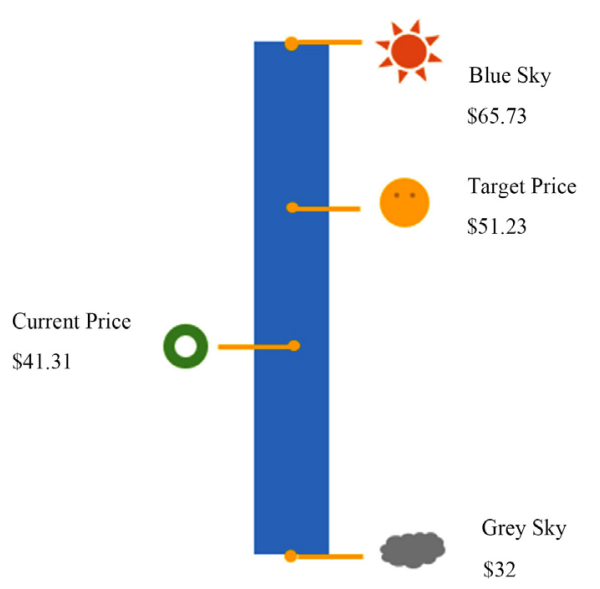

Figure 3. Valuation of Uber. 


\section{Risks}

What's more, Uber's stock carries risks that could affect investors' valuation of the company. First is that Uber would be adversely affected if Drivers were classified as employees instead of independent contractors. Secondly, Uber may fail to develop and successfully commercialize autonomous vehicle technologies and competitors may develop such technologies before Uber, and such technologies may fail to perform as expected, or may be inferior to those developed by Uber's competitors. In addition, the personal mobility, food delivery and logistics are highly competitive and similar products have been around for a long time.

\section{Conflicts of Interest}

The author declares no conflicts of interest regarding the publication of this paper.

\section{References}

[1] Uber's S-1 Filing as of April 11, 2019. http://www.sec.gov/Archives/edgar/data/1543151/000119312519103850/d647752ds $\underline{1 . h t m}$

[2] Uber's Stock Price Data. https://finance.yahoo.com/quote/UBER

[3] Amazon's Historical Stock Price Data. https://finance.yahoo.com/quote/AMZN/history

[4] Amazon's Financials. https://finance.yahoo.com/quote/AMZN

[5] Tesla's Financials. https://finance.yahoo.com/quote/TSLA

[6] Tesla's Historical Stock Price Data. https://finance.yahoo.com/quote/TSLA/history

[7] Expedia's Financials. https://finance.yahoo.com/quote/EXPE

[8] Expedia's Historical Stock Price Data. https://finance.yahoo.com/quote/EXPE/history

[9] GrubHub's Financials. https://finance.yahoo.com/quote/GRUB

[10] GrubHub's Historical Stock Price Data. https://finance.yahoo.com/quote/GRUB/histroy

[11] NetFlix’s Financials. https://finance.yahoo.com/quote/NFLX

[12] NetFlix's Historical Stock Price Data. https://finance.yahoo.com/quote/NFLX/histroy

[13] Booking Holding's Financials. https://finance.yahoo.com/quote/BKNG

[14] Booking Holdings's Historical Stock Price Data. https://finance.yahoo.com/quote/BKNG/histroy 